\title{
The Effect of Water Content on the Combustion Characteristics of Methanol in the Oxy-fuel System
}

\author{
Chih-Yung Wu*1, Bo-Yi Hu² \\ ${ }^{1}$ Department of Aeronautics and Astronautics, National Cheng Kung University, Tainan, \\ Taiwan \\ ${ }^{2}$ International Degree Program on Energy in Engineering, National Cheng Kung University, \\ Tainan, Taiwan \\ ${ }^{*}$ Corresponding author email: cywu@gs.ncku.edu.tw
}

\begin{abstract}
The methanol economy is defined as using methanol as a means of energy carrier. It has been well known that methanol can be produced from waste and biomass or recycled carbon dioxide and water through the catalytic reaction. In a pure oxy-fuel combustion system, the oxidant stream contains only oxygen and carbon dioxide. After the fuel is burned, carbon dioxide and water are the main products. The carbon dioxide in the oxidant stream can be recycled and processed to reduce it to methanol. However, water is produced in the process of making methanol. Moreover, due to methanol's hydrophilic nature; hence, additional energy is required to remove the water from the methanol mixture. In the present study, the effect of water content on the spray combustion characteristics of methanol in the oxy-fuel system is experimentally studied. In the present study, the flame stabilization and the effect of flow rate were observed and characterized. The relationship between the oxygen content in the oxidizer stream and the moisture tolerance's upper limit in the methanol mixture was explored. For combustion efficiency, it can be estimated according to the emission index of CO (EICO). The effect of water content in methanol on flame stabilization, emissions, and relative efficiency is also evaluated. This research provides several important conclusions related to the methanol spray combustion in the oxy-fuel combustion system. Understanding the spray combustion of methanol and its stabilization, emissions, and relative efficiency will serve as the basis for the further high-efficiency application.
\end{abstract}

\section{Keywords}

Spray combustion, Methanol spray combustion, Oxy-fuel.

\section{Introduction}

The feasibility of burning methanol which is heavily contaminated water in the $\mathrm{O}_{2} / \mathrm{CO}_{2}$ atmosphere was evaluated in the present research. This study provides a practical approach that could be applied to burn crude methanol or waste methyl alcohol in the oxy-fuel system. Moreover, the feasibility of direct burning of high-water content methanol, the factors influencing the stability of flame, the characterization of the flames, and the relative thermal efficiency are also evaluated in the present study.

According to the World Meteorological Organization report, the global mean temperature in 2020 reached one of the three warmest on record and continued to increase[1]. Although COVID-19 cut $4.2-7.5 \%$ of $\mathrm{CO}_{2}$ emissions, it is not enough to reduce the increasing global warming trend. Therefore, it is imperative to reduce carbon dioxide emissions from combustion devices today. Oxy-fuel combustion, instead of air, is a burning technique using pure oxygen or a mixture of oxygen and flue gas. In the oxy-fuel burner, nitrogen oxide is wholly reduced, and carbon dioxide can be ready for sequestration. Hence, oxy-fuel combustion is a feasible alternative to removing carbon dioxide from the flue gas. 


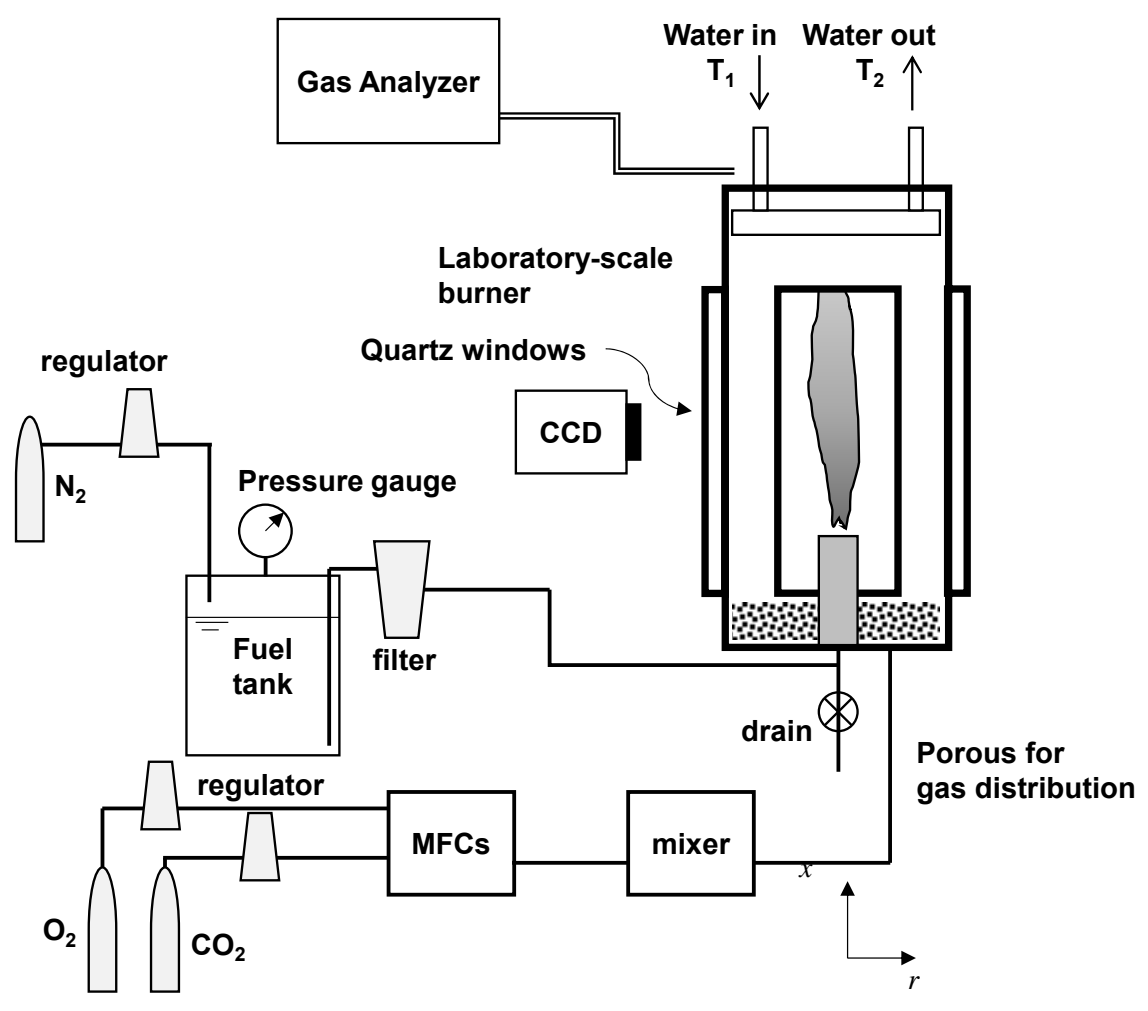

Figure 1. Schematic apparatus.

The hydrogen economy is an alternative solution to reduce $\mathrm{CO}_{2}$ emissions. For the hydrogen economy concept, hydrogen is used as the energy carrier to replace fossil fuels and mitigate global warming. The infrastructure for distribution and transportation, fossil-fuel-free hydrogen manufacturing, and combustion device development are still a challenge due to hydrogen's intrinsic properties. In the 1990s, Nobel prize laureate George A. Olah proposed the methanol economy. It suggested that replacing fossil fuels with methanol or dimethyl ether as a means of the energy carrier, the fuel for vehicles, and the feedstock of chemicals could be feasible[2]. Methanol is a commonly used chemistry and is liquid at ambient temperature and pressure. Therefore, it is easier for transportation and distribution using current infrastructure. Methanol's original name is wood alcohol which is acquired from the distillation of wood. Modern methanol production via suitable catalyst is applying $\mathrm{CO}$ and $\mathrm{H}_{2}$ as the feedstock, which is the main composition of syngas[3]. It has also been reviewed that direct converting $\mathrm{CO}_{2}$ to methanol is feasible despite several challenges[4]. In the methanol manufacturing process, the water content in the product is relatively high[5], and the dehydration process is necessary for the application as fuels. Hence, extra energy consumption for water removal is needed for regular applications. However, the flame stabilization of water content fuels can be improved by increasing oxygen concentration in the oxidizer stream.

Spray combustion has always been the most direct way to convert liquid fuels' chemical energy into thermal energy. The experimental results are necessary for practical systems or the basis for numerical simulations to get the optimized designs. It has been known that the fundamental spray combustion behaviors associated with a full-scale combustor can be evaluated by laboratory-scale spray combustion[7], which is more uncomplicated and easier to operate. 
To mitigate the degradation of the environment and reduce fossil fuel usage, using methanol is a solution. Besides, the methods or policies of applying methanol have also been proposed in several countries[8]. Based on the motivation as mentioned above, the feasibility of this research was evaluated for the following:

1. Methanol was chosen as the primary fuel and blended with water. Methanol can be prepared from biomass and renewable.

2. A pressurized nozzle that is used commonly in the furnace was chosen for the fuel spray. The effect of water content on the spray was also evaluated.

3. The fuel nozzle is installed in a laboratory-scale combustor. The oxidizer stream is well distributed by using a settling chamber and ceramic beads in the combustor.
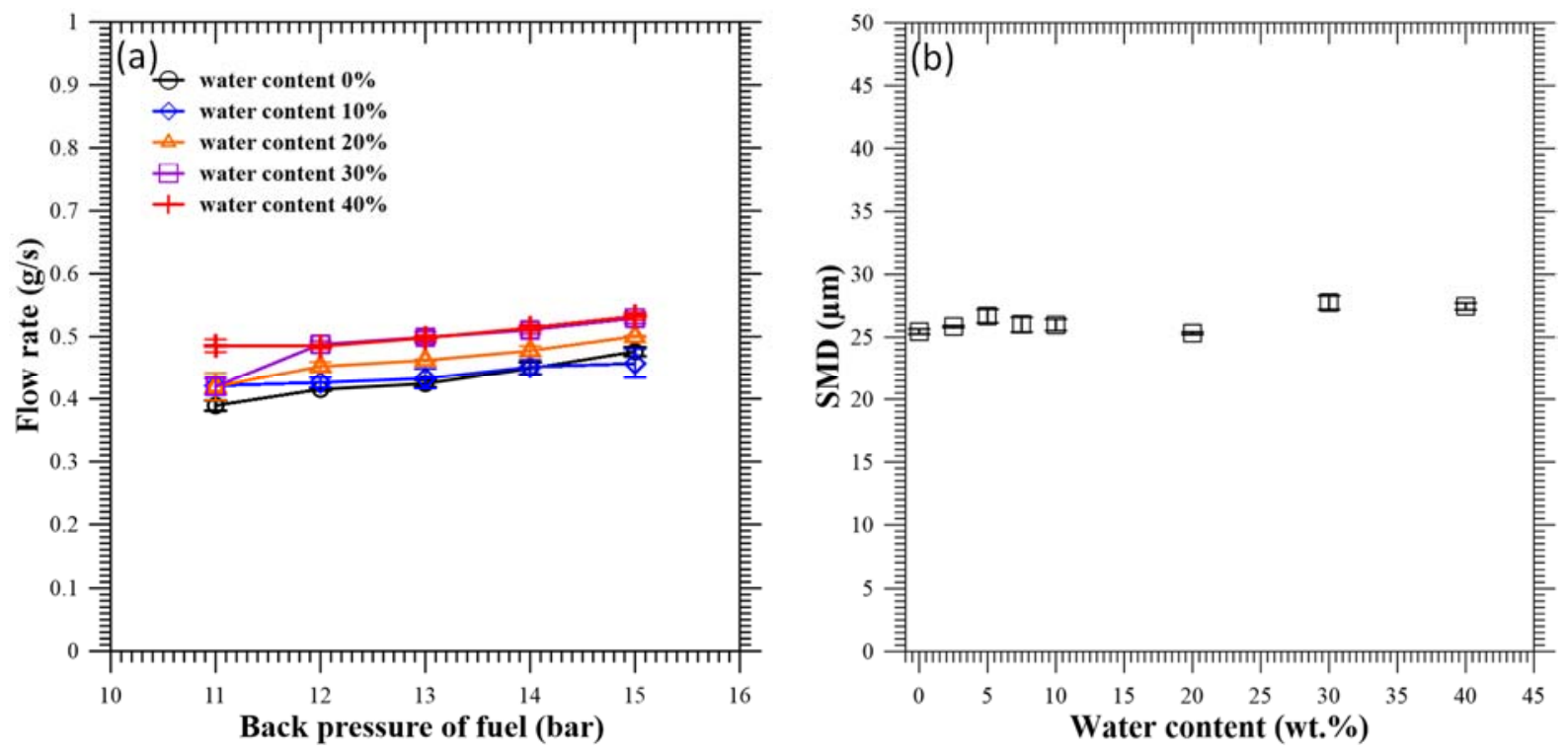

Figure 2. (a) the flowrate of fuel versus the fuel pressure; (b) the SMD versus the water contents in methanol .

\section{Methodologies}

The experimental apparatus is shown in Figure 1. At the bottom of the furnace, the oxidizer stream is distributed using porous media. For the oxidizer stream, oxygen and carbon dioxide are filtered and regulated from the gas cylinders. The flow rate is controlled by the flow mass controllers before flowing into the furnace's settling mixer. All mass controllers were wellcalibrated, and the margin of error is $\pm 1.0 \%$ of the full scale. Methanol was supplied using the pressurized stainless tank, a pressure regulator, and a nitrogen cylinder pressurized. Before the atomizer, methanol was filtered to remove the particulate matter. The atomizer is a commercial pressurized swirling sprayer, and the orifice is $0.15 \mathrm{~mm}$. The flow rate is controlled by tunning the fuel pressure linearly. The averaged mass flow rate varies with the fuel pressure is shown in Figure 2(a). The droplet size of the methanol spray was characterized by the Malvern Spraytec. As shown in Figure 2(b), the Sauter Mean Diameter (SMD) is approximately $25 \mathrm{~m}$ and is not affected by the blended fuel's water content. A lab-made alumina heat exchanger with a water-cooling channel was used to measure the oxygen-fuel furnace's relative thermal efficiency. Water at ambient temperature flows into the alumina heat exchanger and receives the heat generated by the flame. The relative thermal efficiency can be defined by Eq. (1) where $\dot{m}, c_{p}, T_{1}, T_{2}, \dot{Q}_{\text {fuel }}$, and $L H V_{\text {fuel }}$ are water mass flowrate in the 
heat exchanger, heat capacity of water, inlet water temperature, outlet water temperature, fuel flow rate, and the lower heating value of the fuel, respectively.

$$
\eta=\frac{\dot{m} c_{p}\left(T_{2}-T_{1}\right)}{\dot{Q}_{\text {fuel }} L H V_{\text {fuel }}}
$$

Because the exhaust flue gas contains a higher oxygen concentration, the general flue gas analyzer is not suitable. Therefore, the syngas analyzer produced by MRU was applied for exhaust gas measurement, whose model is VARIOluxx, can be used to analyze the concentration of oxygen, carbon monoxide, carbon dioxide, methane, and hydrogen. The flue gas sampling tube was installed on the exit of the laboratory-scale oxyfuel furnace. An emission index (EI) is defined to calculate the weight of product released per kilogram of fuel consumed. In the present study, to study the effect of water content in methanol on oxy-fuel combustion, the fluid pressure was set as 13 bars, and the fuel samples are listed in Table 1.

Table 1 - Experimental condition

\begin{tabular}{ccccc}
\hline $\begin{array}{c}\text { Case } \\
\#\end{array}$ & $\begin{array}{c}\text { Water contents } \\
(\%)\end{array}$ & $\begin{array}{c}\text { Fluid pressure } \\
(\text { bar })\end{array}$ & $\begin{array}{c}\text { Mean fuels flowrate } \\
(\mathrm{g} / \mathrm{s})\end{array}$ & $\begin{array}{c}\text { SMD @ } \mathrm{x}= \\
5 \mathrm{~mm}\end{array}$ \\
\hline 1 & $0^{\dagger}$ & 13 & 0.4241 & 24.83 \\
2 & 2.5 & 13 & 0.4307 & 24.92 \\
3 & 5.0 & 13 & 0.4346 & 25.14 \\
4 & 7.5 & 13 & 0.4334 & 24.14 \\
5 & 10.0 & 13 & 0.4330 & 26.88 \\
6 & 20.0 & 13 & 0.4219 & 25.32 \\
7 & 30.0 & 13 & 0.4625 & 27.75 \\
8 & 40.0 & 13 & 0.4575 & 27.45 \\
\hline
\end{tabular}

t: the water contents in the original methanol is less than $1 \%$

\section{Results and Discussion}

The flame appearances of methanol spray combustion in different oxidizer streams are shown in Figure 3. In the stream of $50 \% \mathrm{O} 2$ blended with $50 \% \mathrm{CO} 2$, the water contents in methanol can not over $10 \%$. The methanol flame plume is lifted and stabilized at a certain height. It can be noted that the lifting height of $10 \%$-water-content methanol is higher than that of pure methanol. In the stream of $60 \% \mathrm{O}_{2}$ blended with $40 \% \mathrm{CO}_{2}$, the flame behaviours are similar to those in the stream of $50 \% \mathrm{O}_{2}$ and $50 \% \mathrm{CO}_{2}$. The colour at the downstream flame is slightly reddish, and it will turn orange as the water content is increased. When the oxygen in the oxidant stream increases to $70 \%$, the water content in methanol can be tolerated at $20 \%$. It is noted that the flame of $0 \%$-water-content methanol and $10 \%$-water-content methanol are almost attached to the sprayer. When the oxygen in the oxidant stream increases to $70 \%$, the water content in methanol can be tolerated at $20 \%$. It is noted that the flame of $0 \%$-watercontent methanol and $10 \%$-water-content methanol are almost attached to the sprayer. As the oxygen in the oxidant stream increases to $80 \%$, all flames are attached to the sprayer, but the tolerated water content is still $20 \%$. If the oxygen in the oxidant stream reaches $90 \%$, the tolerated water content can be extended to $30 \%$, and all flames are attached. 

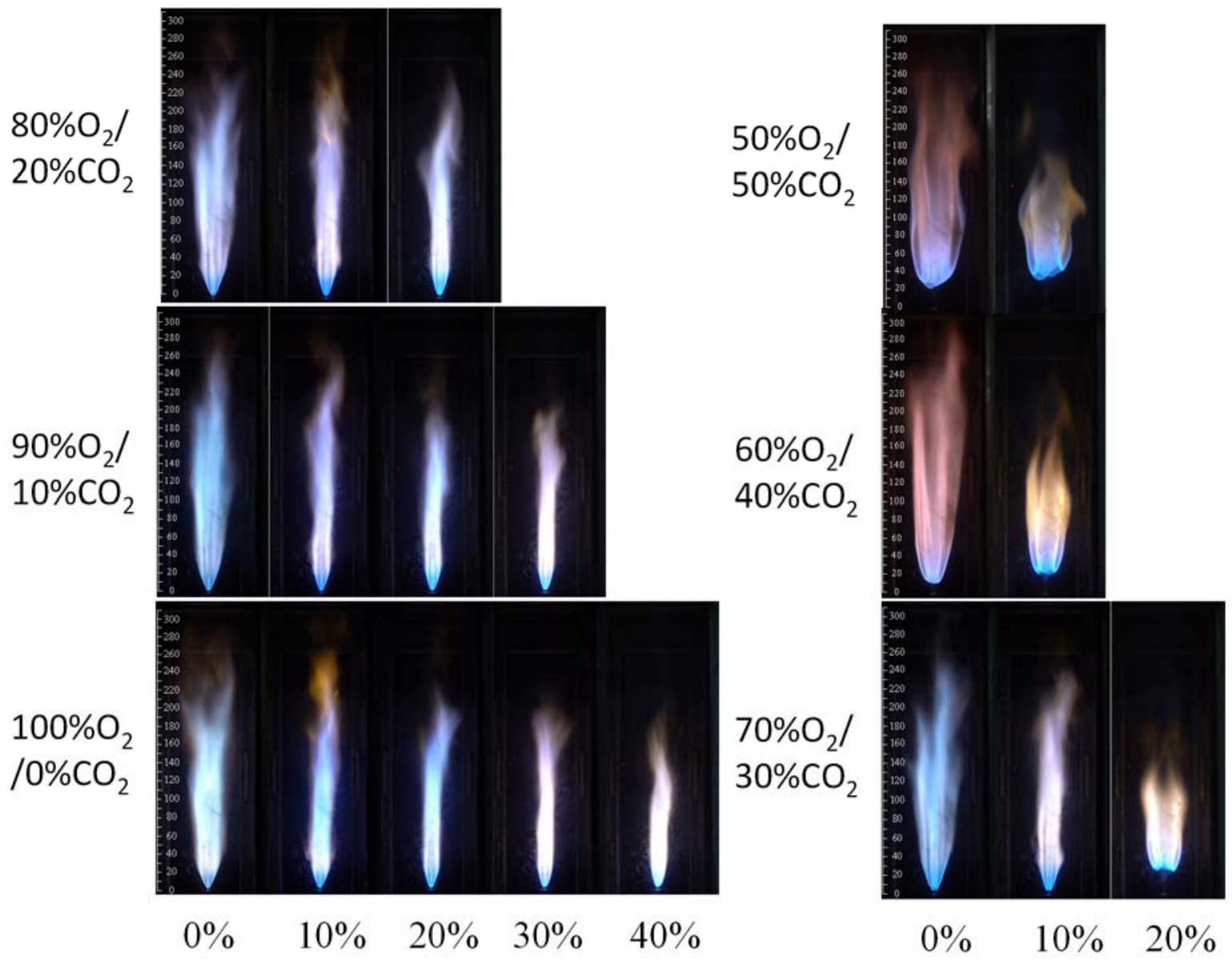

Figure 3 Flame appearances of methanol spray combustion in different oxidizer stream

For the pure oxygen oxidizer stream, the tolerated water content can be further extended to $40 \%$. It can be noted that the flames become is more bright as the oxygen concentration is increased, and the flame colour turns yellow as the water content in methanol is increased.

The tolerated water content in methanol for the different $\mathrm{O}_{2}-\mathrm{CO}_{2}$ oxidizer streams is also be shown in Figure 4. Solid dots in the figure represent stable spray combustion cases, and the hollow dots represent the flame that can be ignited but cannot be sustained stably.

Emission index of carbon monoxide versus the water content in methanol for different O2$\mathrm{CO} 2$ oxidizer streams are shown in Figure 5. For the case of pure methanol spray combustion, the EICO is approximately zero. As the water content in methanol is increased, the EICO is also increased. For the case of $40 \%$-water-content methanol, even in pure oxygen oxidizer stream, the EICO is up to $0.01 \mathrm{~g} / \mathrm{kg}$-fule. The variation in EICO is mainly related to the water content in methanol, and the oxygen content in the oxidant stream has less effect.

Thermal efficiency versus the water content in methanol for different $\mathrm{O}_{2}-\mathrm{CO}_{2}$ oxidizer streams are shown in Figure 6. The thermal efficiency is in the range between 14 and $19 \%$. When the water content in methanol is as high as $40 \%$, its thermal efficiency is greatly reduced. 


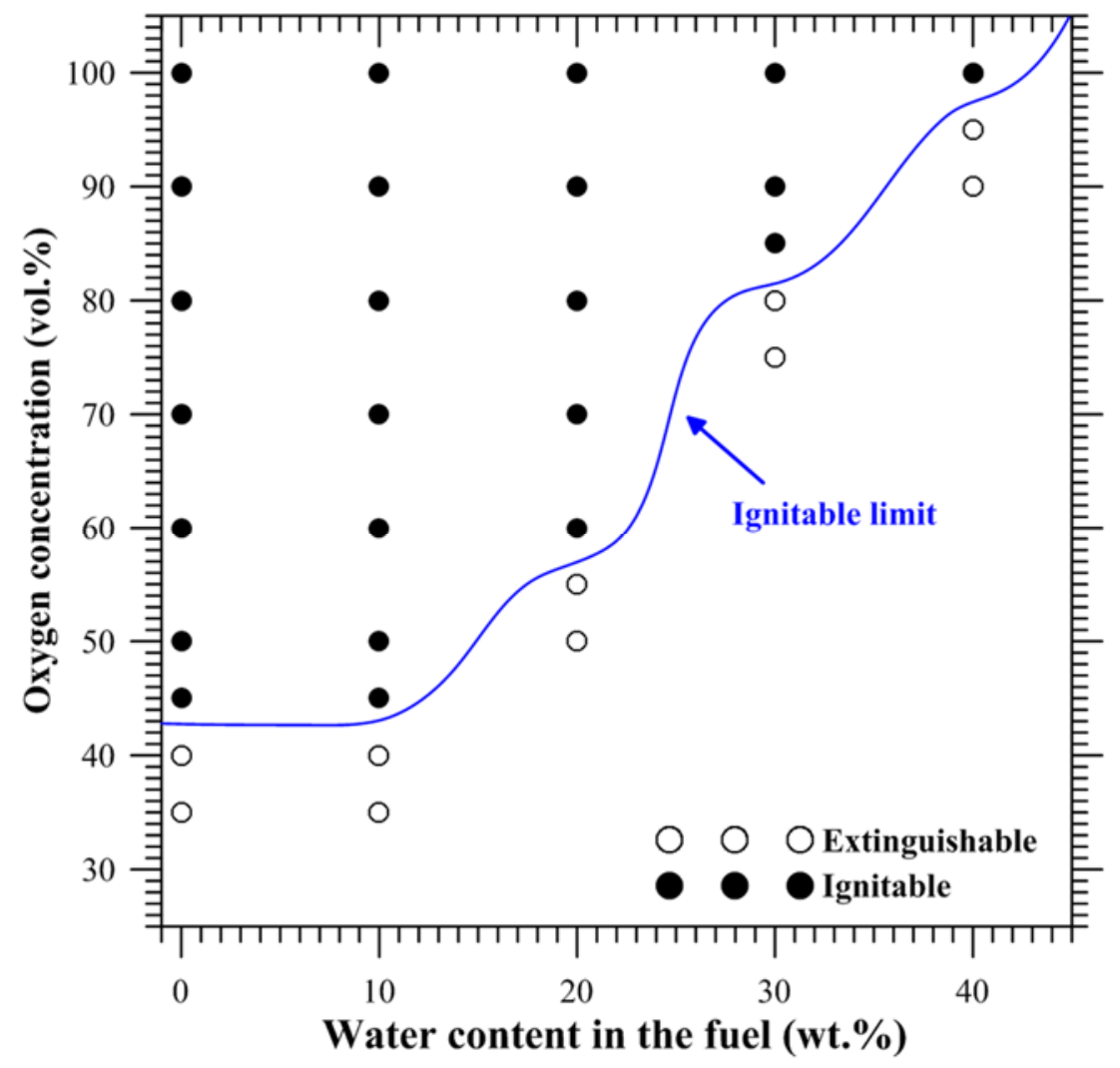

Figure 4 Tolerated water content in methanol for the different $\mathrm{O}_{2}-\mathrm{CO}_{2}$ oxidizer stream

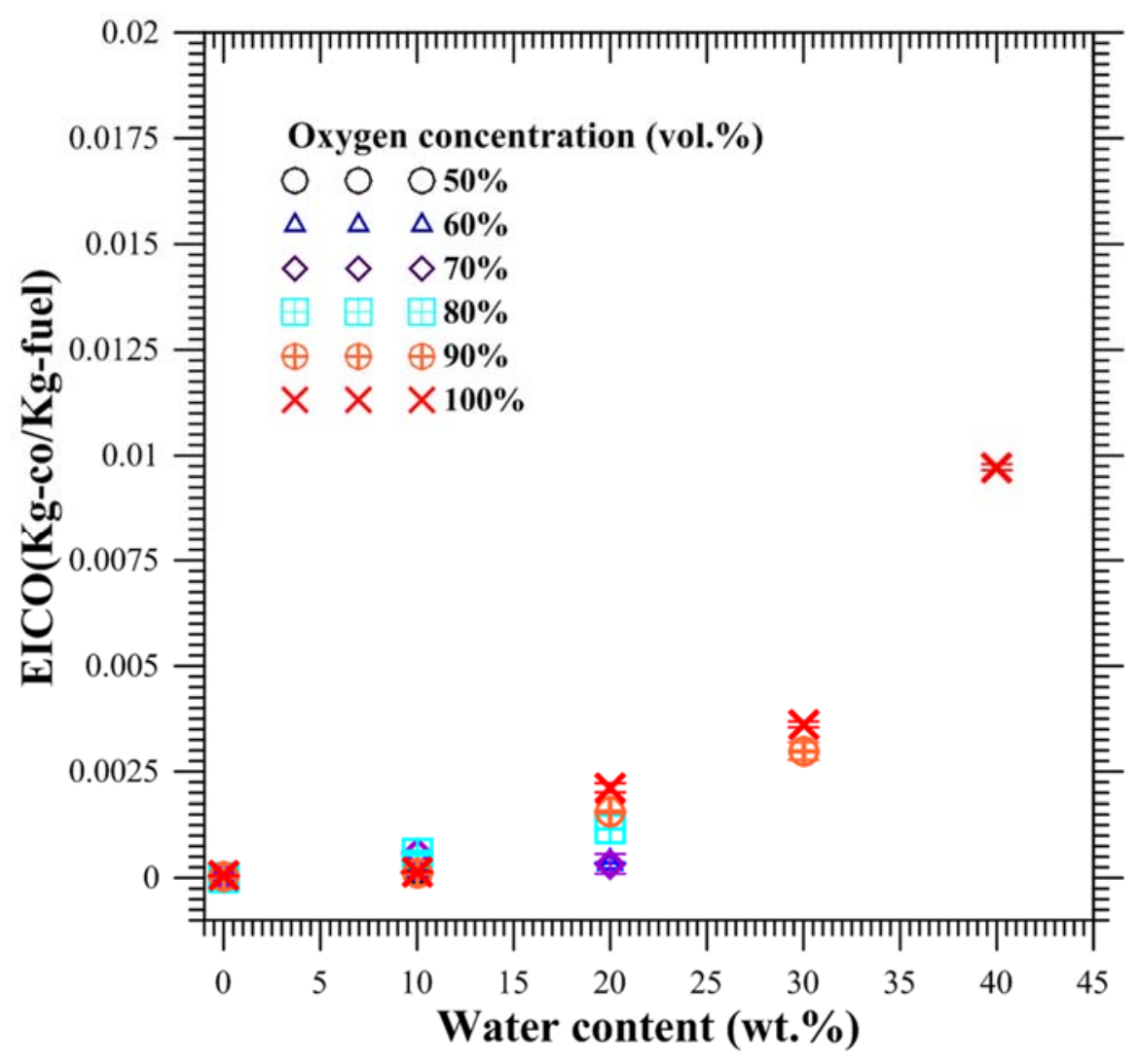

Figure $5 \mathrm{EICO}$ versus the water content in methanol for different $\mathrm{O}_{2}-\mathrm{CO}_{2}$ oxidizer streams 


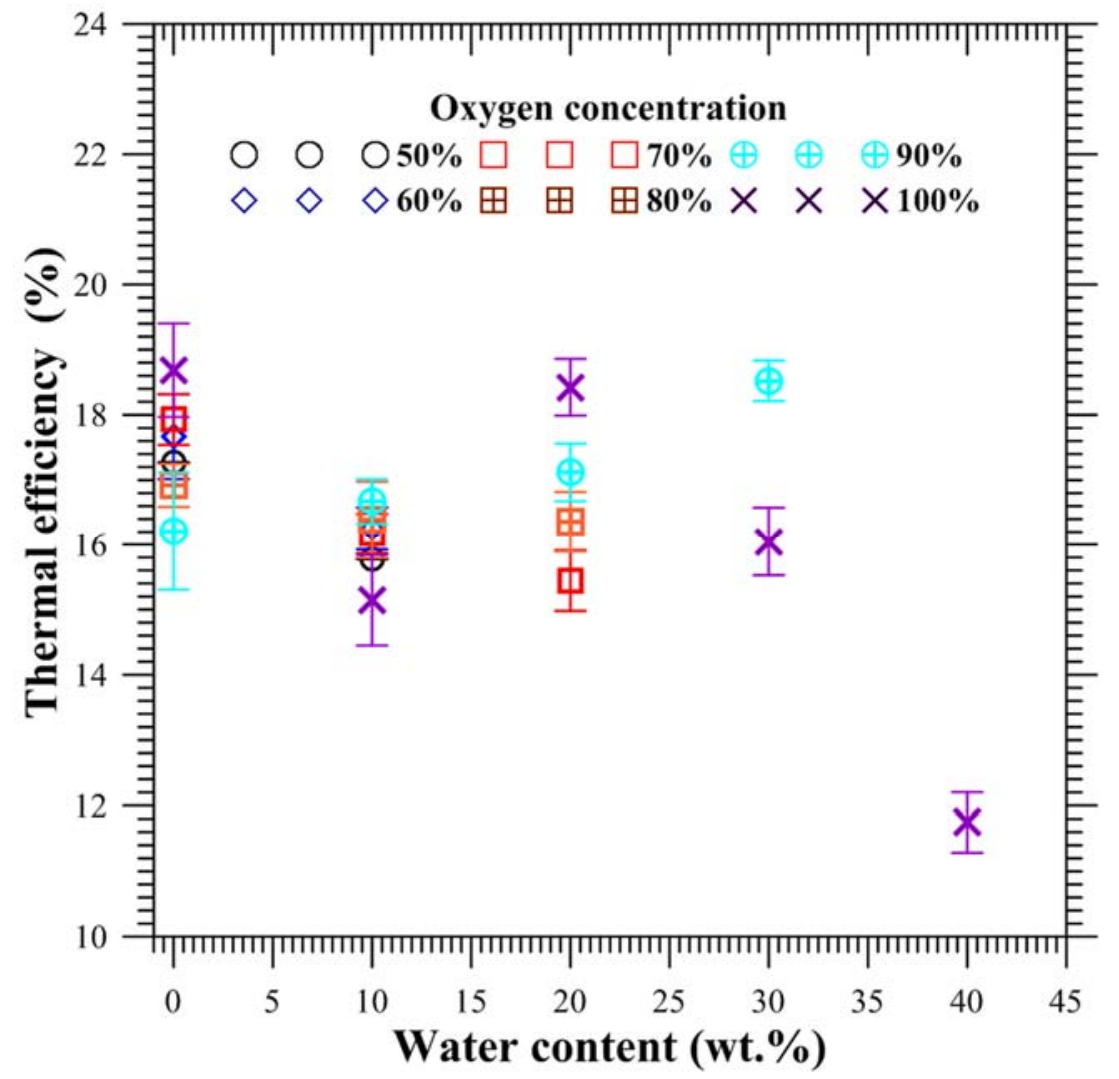

Figure 6 Thermal efficiency versus the water content in methanol for different $\mathrm{O}_{2}-\mathrm{CO}_{2}$ oxidizer streams

\section{Conclusions}

In the present study, the feasibility of burning methanol which is heavily contaminated water in the $\mathrm{O}_{2} / \mathrm{CO}_{2}$ atmosphere was experimentally evaluated. The tolerated water content in methanol mixtures for different $\mathrm{O}_{2}-\mathrm{CO}_{2}$ oxidizer streams, flame appearances, emission index of carbon monoxide, and thermal efficiencies are delineated. The significant conclusions are listed.

1. Basically, the flame colour is blue. The flames become is brighter as the oxygen concentration is increased, and the flame colour turns yellow as the water content in methanol is increased.

2. As the concentration of $\mathrm{O} 2$ in the oxidizer streams in increased, the flame is attached to the sprayer.

3. As the water content in methanol is increased, the EICO is also increased. The variation in EICO is mainly related to the water content in methanol, and the oxygen content in the oxidant stream has less effect.

4. The thermal efficiency is in the range between 14 and $19 \%$, When the water content in methanol is as high as $40 \%$, its thermal efficiency is greatly reduced.

The present study provides several preliminary and important results for the methanol spray combustion in $\mathrm{O}_{2}-\mathrm{CO}_{2}$ oxidizer streams. Understanding the spray combustion of methanol and its stabilization, emissions, and relative efficiency will serve as the basis for the further high-efficiency application.

\section{Acknowledgments}

This research was supported by the Ministry of Science and Technology, Taiwan, under Grant no. MOST 109-2221-E-006-032. 


\section{Nomenclature}

$\dot{m}$

mass flowrate in the heater exchanger $[\mathrm{kg} / \mathrm{s}]$

$c_{p} \quad$ heat capacity of water $[\mathrm{J} / \mathrm{Kg}-\mathrm{K}]$

$T_{1} \quad$ inlet water temperature $[\mathrm{K}]$

$T_{2} \quad$ outlet water temperature $[\mathrm{K}]$

$\dot{Q}_{\text {fuel }} \quad$ fuel flow rate [L/s]

$L H V_{\text {fuel }} \quad$ the lower heating value of the fuel $[\mathrm{J} / \mathrm{L}]$

\section{References}

[1] State of the Global Climate 2020, http:// https://public.wmo.int/en/.

[2] Olah, G.A., Goeppert, A., and Prakash, G.K.S., 2006, "Beyond oil and gas: the methanol economy."

[3] Sehested, J. ,2019, Journal of Catalysis, 371, pp.368-375.

[4] Ganesh, I., 2014, RenewableandSustainableEnergyReviews, 31, pp.221-257.

[5] Pérez-Fortes, M., Schöneberger, J. C., Boulamanti, A., Tzimas, E., 2016, Applied Energy, 161, pp. 718-732.

[6] Yi, F., Axelbaum, R. L., 2013, Proceedings of the Combustion Institute, 34, pp.1697-1704.

[7] Al-Abdeli, Y. M., and Masri, A. R., 2015, Experimental Thermal and Fluid Science, 69, pp. 178-196.

[8] Bonenkamp, T. B., Middelburg, L. M., Hosli, M. O., and Wolffenbuttel, R. F., 2020, Renewable and Sustainable Energy Reviews, 120, 109667. 